\title{
A importância da Gestão de Custos na formação do Preço de Venda: um estudo de caso em uma indústria química de médio-grande porte
}

Cleuber Rafael dos Santos
Graduação em Ciências Contábeis pela Universidade Federal de Uberlândia - UFU
Assistente Financeiro na Secretaria do Estado de Educação de Minas Gerais
E-mail: cleuberrafaelsantos@hotmail.com

Edvalda Araújo Leal Doutorado em Administração pela Fundação Getúlio Vargas - FGV/SP Professora na Universidade Federal de Uberlândia - UFU Av. João Naves de Ávila, 2121. Santa Mônica. Uberlândia/MG. CEP: 38408-100 E-mail: edvalda@facic.ufu.br

Gilberto José Miranda Doutorado em Controladoria e Contabilidade pela Universidade de São Paulo - USP Professor na Universidade Federal de Uberlândia - UFU Av. João Naves de Ávila, 2121. Santa Mônica. Uberlândia/MG. CEP: 38408-100 E-mail: gilbertojm@facic.ufu.br

\section{RESUMO}

O estudo teve como objetivo identificar a influência da gestão de custos para a formação do preço de venda em uma indústria química de médio-grande porte situada na cidade de Uberlândia. Para atingir esse objetivo realizou-se um estudo de caso, sendo a pesquisa caracterizada, também, como descritiva e qualitativa. Os resultados do estudo mostram que na empresa os custos diretos são apurados conforme recomendado na literatura. Contudo, são utilizados critérios de rateio para os custos e despesas fixas e variáveis, adotando um percentual fixo de 18\% para esses gastos. Esse rateio contém um grau de arbitrariedade, uma vez que, por exemplo, a mão de obra direta é rateada entre as duas linhas de produção de acordo com um percentual que é repassado mensalmente pelo gerente de produção para o setor de controladoria.

Palavras-chave: Contabilidade de Custos. Gestão de Custos. Formação do Preço de Venda.

The Importance of cost management in the formation of sale price: A case study of a medium-large chemical company

\section{ABSTRACT}

This case study aimed to identify the influence of cost management on the formation of sale price of a medium-large chemical company in the city of Uberlândia. This 
study is characterized as descriptive and the approach is qualitative. The results show that the company accounts for its direct costs as recommended in the literature. However, the company uses apportionment criteria for fixed and variable costs at a fixed percentage of $18 \%$ for these expenses. This apportionment contains a degree of arbitrariness, because, for example, direct labor is apportioned between the two production lines according to a percentage that is reported monthly by the production manager to the control sector.

Key words: Cost Accounting. Cost Management. Formation of Sale Price.

\section{INTRODUÇÃO}

O atual ambiente econômico e a acirrada concorrência fazem com que os gestores das empresas necessitem de ferramentas que os auxiliem a mantê-las no mercado e se tornarem mais competitivas. Significa dizer que necessitam conhecer adequadamente os custos dos produtos, bem como a formação dos preços de venda.

Atualmente, tem sido uma constante no ambiente empresarial a influência do mercado consumidor em estabelecer o preço que está disposto a pagar pela aquisição de bens e serviços e a consequente perda de poder das empresas em estabelecer o preço pelo qual desejam vender (MACHADO; SOUZA, 2006). Isso requer que os gestores direcionem maiores esforços para o planejamento e controle do consumo dos recursos demandados para a realização de suas operações.

Nesse cenário, percebe-se que a precificação é uma das principais e mais difíceis funções desempenhadas dentro da empresa. Para fixar o preço de venda de um produto é necessário conhecer fatores internos e externos à empresa, tais como custos diretos e indiretos, demanda, concorrência, mercado consumidor, entre outros (HORNGREN et al., 2004).

Assim, esse processo gera muitas discussões e dúvidas, pois um preço formado de maneira inadequada pode trazer consequências negativas para 0 resultado da empresa. Um dos fatores internos que exerce influência significativa na formação do preço de venda são os custos diretos e indiretos. Um equívoco na apuração dos custos pode afetar diretamente a formação do preço de venda. Dessa 
A importância da Gestão de Custos na formação do Preço de Venda: um estudo de caso em uma indústria química de médio-grande porte Cleuber Rafael dos Santos, Edvalda Araújo Leal, Gilberto José Miranda

forma, as empresas têm investido bastante na gestão de custos, de forma a torná-la uma ferramenta útil na formação do preço de venda.

Nesse contexto, o objetivo deste trabalho foi identificar a influência da gestão de custos para a formação do preço de venda em uma indústria química de médiogrande porte situada na cidade de Uberlândia. A pedido do proprietário da empresa adotou-se o nome fictício de "Indústria Química Indy Ltda", visando preservar o nome da empresa.

Para alcançar o objetivo proposto no trabalho, realizou-se um estudo de caso. A metodologia adotada engloba a análise qualitativa com a realização de entrevistas e pesquisa documental na empresa em estudo.

O trabalho está estruturado em cinco partes, sendo a primeira esta introdução. O segundo tópico refere-se ao referencial teórico, no qual é abordada a importância da gestão de custos para tomada de decisão, os principais métodos de custeio utilizados e o modo pelo qual ocorre o processo de formação do preço de venda. A terceira parte trata da metodologia utilizada para atingir os objetivos propostos. A quarta seção apresenta os principais resultados obtidos com o estudo. E, por fim, no quinto tópico são apresentadas as considerações finais, seguidas das referências.

\section{REFERENCIAL TEÓRICO}

\subsection{Gestão e Contabilidade de Custos}

O ambiente no qual as empresas estão inseridas está em constante mudança, verificando-se o aumento da concorrência entre elas. As empresas precisam cada vez mais de novas formas para gerenciar seus recursos de modo a reduzir os custos, aumentar a produtividade e satisfazer os clientes (BRAGA et al., 2010). Os gestores não necessitam apenas de informações para controle, mas, principalmente, informações que permitam que eles tenham uma visão holística do negócio que possa the auxiliar no desempenho de suas diversas funções (CARDOSO; BEUREN, 2010). Desse modo, a Gestão de Custos tornou-se uma importante ferramenta de auxílio no processo de tomada de decisão. 
A importância da Gestão de Custos na formação do Preço de Venda: um estudo de caso em uma indústria química de médio-grande porte Cleuber Rafael dos Santos, Edvalda Araújo Leal, Gilberto José Miranda

Com isso, observa-se que a Contabilidade de Custos vem ampliando seu foco, não ficando restrita somente aos aspectos relacionados ao controle do patrimônio. De acordo com Bruni e Famá (2004, p. 237), "na Gestão Empresarial a ênfase deve estar baseada nas decisões tomadas e seus efeitos subsequentes. Nem sempre rotinas e procedimentos contábeis mostram-se adequados ao auxílio do processo de tomada de decisões".

Uma das principais funções desempenhadas pela Contabilidade de Custos é auxiliar a tomada de decisão. Martins (2008, p. 22) diz que

(...) no que tange à decisão, seu papel reveste-se de suma importância, pois consiste na alimentação de informações sobre valores relevantes que dizem respeito às consequências de curto e longo prazo sobre medidas de introdução ou corte de produtos, administração de preços de venda, opção de compra ou produção, etc.

Segundo Leone (2000), a Contabilidade de Custos é um centro processador de informações, onde os dados são coletados, organizados, interpretados e analisados pelo contador, gerando informações para diversos usuários de diferentes níveis hierárquicos. Assim, pode-se perceber que a Contabilidade de Custos é um sistema que fornece diversas informações aos seus usuários de modo a permitir que esses tomem suas decisões de maneira mais adequada.

\subsection{Os Métodos de Custos para Tomada de Decisão}

O principal problema enfrentado na gestão de custos é a alocação dos custos indiretos. Uma das alternativas encontradas para tentar solucionar esse problema é a não utilização de rateios dos custos indiretos, pois no processo decisório a realização de rateios de maneira errada pode fazer com que o gestor tome decisões equivocadas (BRUNI, 2008). Dessa forma, pode-se perceber uma estreita relação entre os métodos de custeio e processo de tomada de decisão.

O gestor da empresa para tomar suas decisões precisa de uma série de informações sobre os custos dos produtos. De acordo com Ribeiro (2009), existem diversos sistemas que podem ser usados para custear os produtos, sendo que uns 
têm a finalidade de alocar os custos indiretos como o sistema de custeio departamental e sistema de custeio $\mathrm{ABC}$; e outros têm a finalidade de alocar o custo total ao produto como os sistemas de custeio variável, por absorção (Reichskuratorium für Wirtschaftlichtkeit-RKW). Então, para este trabalho serão analisados apenas três métodos de custeio: Custeio por Absorção, Variável e ABC.

Bruni e Famá (2004, p. 181) complementam que

os sistemas de custeio atuais foram criados há cerca de um século. Seus principais objetivos consistem na geração de informações sobre oportunidades de melhorias dos desempenhos das empresas, em termos do resultado econômico. No entanto, com as alterações nos panoramas dos negócios, os sistemas tradicionais começaram a ser questionados. Muitas das técnicas têm-se revelado inúteis no auxílio das decisões empresariais.

O Método de Custeio por Absorção consiste no emprego dos princípios básicos da Contabilidade, em que todos os custos e esforços são alocados aos produtos (MARTINS, 2008). Assim, procede-se à separação dos custos e despesas, sendo os custos diretos alocados diretamente aos produtos, e os indiretos passam pelo processo de rateio. Então, apenas as despesas farão parte do resultado do exercício (RIBEIRO, 2009).

O Custeio por Absorção é amplamente utilizado, principalmente, pelo fato de ser aceito pela legislação fiscal e societária e, também, devido à dificuldade de se manter um sistema paralelo para fins gerenciais. O principal problema existente no Custeio por Absorção é a arbitrariedade no rateio dos custos indiretos, diminuindo a qualidade das informações para fins de decisão. Para Martins (2008), todo critério de rateio contém um grau de subjetivismo, fazendo com que haja arbitrariedade na alocação dos custos. Portanto, faz-se necessário buscar novas formas e técnicas para diminuir essa arbitrariedade.

Como uma forma de eliminar a arbitrariedade existente nos critérios de rateio tem-se o Método de Custeio Variável, no qual apenas os gastos variáveis fazem parte do custo dos produtos; os custos fixos, em conjunto com as despesas, integram o resultado do exercício. No entanto, esse método não é aceito para fins 
A importância da Gestão de Custos na formação do Preço de Venda: um estudo de caso em uma indústria química de médio-grande porte Cleuber Rafael dos Santos, Edvalda Araújo Leal, Gilberto José Miranda

fiscais, uma vez que ele pode subavaliar o resultado do exercício por um determinado período de tempo (RIBEIRO, 2009).

Sob a ótica gerencial, o Custeio Variável fornece um número maior de informações, além de oferecer maior agilidade de modo a auxiliar os gestores na tomada de decisão. Assim, esse método de custeio possui um poder maior de informação, visto que trata os custos fixos separados como se fossem despesas, não havendo a necessidade de rateio. Apesar desse método não ser aceito pelo fisco, nada impede sua adoção nas empresas para fins gerenciais (MARTINS, 2008).

Com o desenvolvimento do ambiente produtivo, houve um aumento das linhas de produção e da variedade de produtos e serviços. Com isso, os custos indiretos passaram a ser alocados nas atividades desenvolvidas pelas empresas. Assim, o Custeio Baseado em Atividades $(A B C)$ se distingue dos métodos tradicionais de custeio por alocar os custos nas atividades desenvolvidas nas empresas por meio dos direcionadores de custos, sendo um método mais coerente de alocação dos custos (BRUNI; FAMÁ, 2004).

Martins (2008) complementa mencionando que o Custeio ABC é um método que veio tentar diminuir os efeitos negativos da arbitrariedade dos rateios dos custos indiretos. Vale destacar que o Custeio $A B C$ não fica restrito apenas ao custeio dos produtos, visto que esse método também é uma importante ferramenta usada na gestão de custos das organizações.

\subsection{Formação do Preço de Venda}

A formação do preço de venda dos produtos representa um importante elemento econômico-financeiro em qualquer organização. $O$ desempenho satisfatório de uma empresa depende muito da adequada formação do preço de venda, uma vez que um preço equivocado de um produto pode the causar sérios problemas (PUFF et al., 2006).

A gestão de custos desempenha um papel relevante na formação do preço de venda dos produtos. Além dos custos, o processo de formação de preço depende de outras variáveis, como as condições do mercado, o nível de atividade e a 
remuneração do capital investido. Assim, a fixação do preço de venda de maneira adequada provoca a maximização dos lucros, atende os desejos dos clientes e aproveita de maneira mais eficiente os níveis de produção (BRUNI; FAMÁ, 2004).

Para Horngren et al. (2004, p. 385), "o preço de um produto ou serviço depende da oferta e da procura. As três influências que incidem sobre a oferta e a procura são: os clientes, os concorrentes e os custos". Os clientes influenciam o preço, pois são esses que criam a demanda por um produto ou serviço. Produtos e serviços com preços altos podem fazer com que os clientes os substituam por outros mais acessíveis. É preciso também conhecer a tecnologia aplicada, a capacidade instalada e a política adotada pelos concorrentes como uma forma de se estimar os custos dos mesmos. Os custos estão intimamente ligados à oferta, uma vez que, quanto menor o custo de produção de um produto em relação ao preço pago pelo cliente, maior será a capacidade de fornecimento. Assim, para maximizar o lucro da empresa, é necessário ter preços atraentes para os consumidores e, ao mesmo tempo, calcular os custos relevantes, englobando toda a cadeia de valor (HORNGREN et al., 2004).

Segundo Bruni e Famá (2004), no processo de formação do preço de venda podem-se utilizar três métodos diferentes, baseando-se nos custos, no consumidor ou na concorrência.

No processo baseado nos custos, costuma-se apurar os custos dos produtos e, com base no valor apurado, acrescenta-se uma margem de lucro, ou seja, o preço de venda é a soma do custo do produto com a margem de lucro esperada pela empresa. Diversas são as justificativas para a fixação do preço de venda por esse método, como, por exemplo, a simplicidade e segurança. No entanto, a aplicação exclusiva desse método pode trazer uma série de consequências negativas, uma vez que é necessário também considerar a demanda e a concorrência (BRUNI; FAMÁ, 2004).

Para se chegar ao preço de venda, utiliza-se o mark-up, que consiste em aplicar um índice sobre os gastos de determinado bem ou serviço, obtendo-se, assim, o preço de venda. Segundo Padoveze (2004, p. 421), "a partir do custo por absorção de cada produto, aplica-se um multiplicador, de tal forma que os demais 
elementos formadores do preço de venda sejam adicionados ao custo, a partir desse multiplicador". Embora o mark-up seja um índice aplicado sobre os custos dos produtos e serviços, a sua construção está ligada ao preço de venda. Todos os componentes do mark-up são determinados por meio de relações percentuais sobre o preço de venda e, em seguida, são aplicados sobre os custos dos produtos (PUFF et al., 2006).

O mark-up é uma técnica que serve de base para a formação de preço de venda de produtos, pois define uma porcentagem a ser aplicada sobre o custo para se chegar ao preço de venda ao cliente. Em muitas empresas se utiliza um mark-up que tem por finalidade cobrir: os impostos sobre vendas; as despesas variáveis sobre vendas; as despesas administrativas fixas; as despesas de vendas fixas; os custos indiretos de produção fixos; e o lucro (BRUNI; FAMÁ, 2004).

Os autores abordam outra forma de fixação do preço de venda com base no valor percebido do produto pelo mercado consumidor, ou seja, os preços são ajustados de acordo com a percepção que os consumidores têm do produto e não de acordo com os custos do vendedor. Com esse método busca-se conhecer o preço que o cliente está disposto a pagar pelo produto, devendo-se estipular o maior preço de modo a maximizar os resultados.

Já no terceiro método se utiliza a análise da concorrência para fixar o preço de venda, dando pouca importância aos custos e à demanda. Nesse caso a concorrência é a maior influenciadora na formação do preço de venda (BRUNI; FAMÁ, 2004). No entanto, Puff et al. (2006, p. 7) advertem que "as empresas que usam esse método têm que tomar alguns cuidados, pois os custos de uma empresa para outra não são os mesmos e dependendo do preço de venda que captarem da concorrência podem não cobrir os seus custos".

Assim, pode-se perceber que para uma adequada formação do preço de venda é necessário levar em consideração as três variáveis em conjunto, uma vez que se elas forem tratadas de maneira isolada elas podem afetar a precificação, trazendo consequentemente resultados negativos para a empresa. 
A importância da Gestão de Custos na formação do Preço de Venda: um estudo de caso em uma indústria química de médio-grande porte Cleuber Rafael dos Santos, Edvalda Araújo Leal, Gilberto José Miranda

\section{METODOLOGIA}

No que concerne ao seu objetivo, esta pesquisa classifica-se como descritiva, pois visa descrever os principais fatores relacionados à gestão de custos que influenciam na formação do preço de venda em uma indústria química de médiogrande porte, analisando-os, detalhando-os e interpretando-os (ANDRADE, 2004).

No que diz respeito aos procedimentos adotados, este estudo se classifica como um estudo de caso em uma indústria de médio-grande porte situada na cidade de Uberlândia. Segundo Raupp e Beuren (2008), os procedimentos dizem respeito ao modo pelo qual a pesquisa é conduzida na obtenção dos dados. Gil (2002) afirma que a definição do procedimento a ser utilizado é de extrema importância para que se faça o delineamento da pesquisa.

Para orientar e dar maior confiabilidade ao estudo de caso, foi elaborado um protocolo. Conforme Martins (2008, p.74), "o ponto central do protocolo [...] é um conjunto de questões que, de fato, refletem a investigação real. As questões são feitas ao próprio pesquisador e funcionam como um check list para que o investigador se lembre de todas as ações para condução do trabalho".

Quanto à abordagem do problema a pesquisa se classifica como qualitativa, uma vez que foram realizadas entrevistas com os gestores da empresa, não se valendo de nenhum método quantitativo para se chegar aos resultados.

Richardson (1989, p. 80) afirma que "os estudos que empregam uma metodologia qualitativa podem descrever a complexidade de determinado problema, analisar a interação de certas variáveis, compreender e classificar processos dinâmicos vividos por grupos sociais".

Para a coleta de dados foram realizadas entrevistas com os gestores da organização, bem como uma pesquisa documental. A entrevista é o método em que o entrevistador apresenta-se pessoalmente e formula perguntas, com o objetivo de obter os dados necessários (COLAUTO; BEUREN, 2008). A pesquisa documental foi realizada nos relatórios de controle de custos e demonstração do resultado fornecido pela empresa em estudo. 
As entrevistas foram realizadas pessoalmente através de agendamentos de horário com o controller da organização em estudo, com a analista de custos, com o gerente de vendas, com o diretor de vendas e com o diretor de informática.

O material coletado por meio de entrevistas foi analisado mediante a utilização da técnica de análise de conteúdo. Essa técnica, de acordo com Colauto e Beuren (2008, p. 137), "tem por objetivo estudar as comunicações entre os homens, com maior ênfase no conteúdo das mensagens". A análise de conteúdo deve estar relacionada intimamente ao objetivo da pesquisa, e o pesquisador deve dominar o tema abordado na pesquisa para melhor sustentar a análise dos dados coletados.

A principal limitação do estudo se refere à generalização dos resultados, sendo adequado observar que não existe qualquer limitação no sentido de reproduzir a pesquisa em outras indústrias do mesmo porte, desde que observada a metodologia utilizada neste estudo. A esse respeito, Yin (2005, p.29) explica que, em se tratando de estudos de caso, ao se fazerem generalizações, da mesma maneira que nos experimentos, deve-se fazê-las em relação às proposições teóricas, e não a populações ou universos.

\section{ANÁLISE DOS RESULTADOS}

\subsection{Caracterização da Organização}

De acordo com a Associação Brasileira de Indústrias Químicas (2011) a Indústria Química é um dos mais importantes setores da economia brasileira, estando entre as dez maiores no ranking da indústria química mundial. Internamente, ela é o quarto maior setor da economia brasileira, respondendo no ano de 2010 por $2,4 \%$ do Produto Interno Bruto (PIB), com um faturamento de US\$ 130,2 bilhões. A indústria química é dividida em dois grandes grupos, sendo o primeiro de produtos químicos de uso industrial, formado por produtos orgânicos e inorgânicos, resinas, elastômeros, produtos e preparados químicos diversos. O segundo grupo é o de produtos químicos de uso final, composto por produtos farmacêuticos, higiene pessoal, perfumaria e cosméticos, adubos e fertilizantes, sabões, detergentes e produtos de limpeza, defensivos agrícolas, tintas, esmaltes e 
A importância da Gestão de Custos na formação do Preço de Venda: um estudo de caso em uma indústria química de médio-grande porte Cleuber Rafael dos Santos, Edvalda Araújo Leal, Gilberto José Miranda

vernizes e outros. Dentro dessa classificação, a empresa em estudo se enquadra no segundo grupo.

A Indústria Química Indy Ltda foi fundada em setembro de 1987, iniciando suas atividades com a fabricação de produtos para a limpeza de automóveis. A partir de então, vem expandindo sua linha de produtos e sua área de atuação por todo o Brasil e, também, exportando para países da América, Europa e África. Com o aumento da sua gama de produtos, possui hoje mais de mil itens em sua linha de produção e mais de noventa marcas em atividade, fornecendo soluções de limpeza e higienização para laticínios, frigoríficos, mineradoras, indústrias de alimentos, clubes, condomínios, hotéis, motéis, lavanderias, hospitais, restaurantes, escritórios, residências e produtos para linha automotiva e agropecuária. Possui, atualmente, cerca de 350 colaboradores diretos em seu quadro de funcionários.

Segundo o Banco Nacional de Desenvolvimento (2012) o porte das empresas pode ser classificado de acordo com a Receita Operacional Bruta anual conforme é mostrado a seguir:

Tabela 01: Classificação do porte das empresas

\begin{tabular}{|c||c||}
\hline Classificação & Receita operacional bruta anual \\
\hline \hline Microempresa & Menor ou igual a $\mathrm{R} \$ 2,4$ milhões \\
\hline \hline Pequena empresa & Maior que $\mathrm{R} \$ 2,4$ milhões e menor ou igual a $\mathrm{R} \$ 16$ milhões \\
\hline \hline Média empresa & Maior que $\mathrm{R} \$ 16$ milhões e menor ou igual a $\mathrm{R} \$ 90$ milhões \\
\hline \hline Média-grande empresa & Maior que $\mathrm{R} \$ 90$ milhões e menor ou igual a $\mathrm{R} \$ 300$ milhões \\
\hline \hline Grande empresa & Maior que $\mathrm{R} \$ 300$ milhões \\
\hline \hline
\end{tabular}

Fonte: Banco Nacional de Desenvolvimento (BNDS) 
A importância da Gestão de Custos na formação do Preço de Venda: um estudo de caso em uma indústria química de médio-grande porte Cleuber Rafael dos Santos, Edvalda Araújo Leal, Gilberto José Miranda

A empresa em estudo apresentou uma Receita Operacional Bruta de $R \$ 150$ milhões no ano de 2011. Então, com base na tabela acima a Indústria Química Indy é classificada como uma empresa de médio-grande porte.

\subsection{Formação do Preço de Venda na Indústria Química Indy}

Segundo informações obtidas na empresa em estudo, a formação do preço de venda até o mês de março de 2011 era feita de maneira não automatizada. Todo o processo de formação do preço de venda era registrado em planilhas Excel pelo departamento comercial e, posteriormente, as informações eram repassadas para o Sistema MGE. O MGE é o principal sistema integrado da empresa, sendo utilizado pelos departamentos financeiro, comercial, de produção, de compras, de logística, pelo laboratório e pela controladoria. Devido à necessidade de automatização do processo de formação do preço de venda, atualmente, a empresa possui um software próprio específico para esse fim.

$\mathrm{Na}$ entrevista realizada com o diretor de informática, responsável pela criação do software de formação do preço de venda, verificou-se o modo pelo qual o cálculo do preço de venda é feito e como esse processo foi automatizado. Assim, de acordo com o diretor de informática, esse software faz uma interface com o sistema principal da empresa (MGE), buscando os dados de clientes e os custos diretos para, então, adicionar os outros custos indiretos, como fretes, impostos, comissões, bem como a margem de lucro, para se chegar ao preço de venda, o qual é repassado, novamente, ao MGE. Conforme o depoimento do gerente comercial, "o processo era muito manual e não tinha condições de levar em conta todas as variáveis que precisam ser consideradas no preço. Então, com a automatização você passa a ter condição de colocar todas as variáveis necessárias no preço" (informação verbal).

De acordo com o Controller da empresa, o processo de formação do preço de venda começa no momento da compra, com a entrada das informações constantes nas notas fiscais do material direto no sistema. Com base em uma fórmula préformatada, em que se retiram os impostos e agrega o valor do frete sobre compras, chega-se, então, ao custo do material direto. Dessa forma, com base nesse controle 
de entrada de notas fiscais, é possível conhecer o custo de material direto de cada produto acabado.

É feito um controle muito rigoroso dos custos de material direto. Se ocorrer variação de custo acima ou abaixo de $5 \%$, o sistema não permite o lançamento da nota, sendo necessário que a analista de custos autorize o lançamento. De acordo com o controller,

Os custos vão entrando, mas a gente não vai atualizando a fórmula dos produtos finais todos os dias [...]. Uma vez por semana a gente atualiza o custo dos produtos finais; a gente faz uma conferência bem rigorosa se existe uma variação ou se não existe [...]. Qualquer lançamento acima de $5 \%$ a nota trava e precisa ser liberada por uma pessoa (informação verbal).

Segundo o controller, a empresa possui mais de mil fórmulas de produtos. Os custos de material direto e os custos dos produtos finais são atualizados semanalmente. A empresa designou uma pessoa para realizar esse processo de atualização, devido à sua grande complexidade, pois o número de fórmulas dos produtos é expressivo.

De acordo com a analista de custos, quando há alguma variação do custo do produto é realizada uma análise para saber a causa. Segundo essa analista, a variação do custo pode ocorrer por diversos motivos, quais sejam: aumento ou redução do preço da matéria prima, alteração da composição da fórmula do produto (aumento ou diminuição de certa quantidade de determinada matéria prima de um produto), entrada da nota fiscal no sistema de maneira incorreta, troca de fornecedores (que podem vender mais caro ou mais barato), alteração da embalagem do produto, a localização do fornecedor, fornecedor optante pelo simples permite aproveitamento de crédito a uma alíquota reduzida, entre outros.

Assim, pode-se perceber que é realizado um controle bem rigoroso do custo do material direto que faz parte do produto acabado, o qual ocorre desde a entrada da nota fiscal no sistema até o seu acompanhamento semanal através da atualização dos custos, permitindo uma alocação bastante confiável aos produtos. 
De posse do custo do material direto, é possível formar o preço de venda, fazendo-se estimativas dos demais custos. Em conversa com o Gerente Comercial, o mesmo forneceu a seguinte fórmula para a formação do preço de venda:

$\begin{gathered}\text { Preço de } \\ \text { Venda }\end{gathered}=\frac{\text { Custo do Material Direto }}{1-(\text { Custos Fixos + Margem de Lucro + Comissão + ICMS + PIS/COFINS) }}+\frac{\text { Frete sobre vendas }}{1-(\text { Comissão }+ \text { ICMS + PIS/COFINS })}+\frac{\text { Encargos }}{\text { Financeiros }}$

Foram realizadas algumas simulações pelo autor e percebeu-se que a fórmula acima tem algumas incorreções. Pode-se notar que os fretes e encargos financeiros são tratados à parte. Assim, se o preço de venda formado com base na fórmula acima for tomado para cálculo de cada item que o compõe, chega-se a valores diferentes daqueles que efetivamente ocorreram. Por exemplo, suponha-se que um determinado produto tenha custo de material direto de $\$ 1000,00$ e fretes de $\$ 50,00$, o percentual da comissão de $5 \%$, os impostos $9 \%$, encargos financeiros $2 \%$, custos fixos (médios) 18\% e a margem de lucro de 20\%. Aplicando esses dados na fórmula apresentada, tem-se um preço de venda igual a $\$ 2.244,00$. Se esse valor for tomado para cálculo dos percentuais acima, constata-se uma diferença de $\$$ 23,32 na conta final.

Assim, em uma conversa posterior com o controller da empresa, foram questionados esses erros e o mesmo fez algumas correções, apresentando a seguinte fórmula:

$$
\begin{gathered}
\text { Preço de } \\
\text { Venda }
\end{gathered}=\frac{\text { Custo do Material Direto + Frete sobre Vendas }}{1-(\text { Custos Fixos }+ \text { Margem de Lucro + Comissão }+ \text { ICMS + PIS/COFINS })}+\frac{\text { Encargos }}{\text { Financeiros }}
$$

Matematicamente, a fórmula ainda poderia ser melhorada, pois o problema não foi totalmente resolvido. O ideal seria alocar, também, os encargos financeiros no denominador da equação.

Para melhor entender a fórmula, bem como a interface entre a estrutura de custos e o preço de venda, será detalhada cada variável que a compõe. O custo do material direto é apurado no momento de entrada da nota fiscal, sendo feito um acompanhamento semanal, conforme mencionado anteriormente. Nesse custo, não 
estão inclusos os impostos incidentes (ICMS e PIS/COFINS), porém, acrescenta-se o valor do frete sobre compras. De acordo com Martins (2008), os custos com materiais diretos, como matérias primas, embalagens e outros, são apropriados aos produtos por seu valor histórico de aquisição. Verifica-se, então, que a empresa adota o método de alocação dos custos diretos, conforme recomenda literatura.

Segundo o Controller, os custos fixos englobam os custos administrativos e comerciais e os custos de fabricação. Com base no histórico da empresa, esses custos representam, aproximadamente, $18 \%$ dos custos totais. Assim, percebe-se que há arbitrariedade na alocação desses custos fixos, uma vez que a empresa se baseia em estimativas para sua alocação. De acordo com Bruni e Famá (2004), no processo decisório, um rateio de custos fixos feito de maneira inadequada pode trazer uma série de consequências negativas, como o corte de produtos lucrativos, por exemplo.

Percebe-se, ainda, que a empresa não separa custos e despesas. Essa estimativa de $18 \%$ para custos fixos engloba tanto custos de produção como despesas com mão de obra, por exemplo. Martins (2008) enfatiza que não é possível fazer essa separação de custos e despesas de maneira clara e objetiva. Para o autor, o mais correto seria utilizar critérios menos arbitrários para ratear apenas os gastos relevantes que contenham tanto elementos de custos quanto de despesas.

A margem de lucro e a comissão são variáveis para cada produto. Segundo o Gerente Comercial, o valor da margem vai depender de uma série de variáveis, como o preço que o mercado está disposto a pagar pelo produto e todas as demais variáveis da fórmula de formação do preço de venda, quais sejam: os valores dos custos diretos e indiretos, fretes, tributos, entre outros. De acordo com o Diretor de vendas da Indústria Química Indy, a empresa trabalha com representantes comerciais autônomos e cada produto tem seu percentual de comissão atrelado à sua rentabilidade.

Através da fórmula de formação do preço de venda, observa-se que a empresa utiliza a técnica do mark-up para precificar os seus produtos. Além de considerar os custos de produção, a empresa também considera outras variáveis, 
como a concorrência e o mercado consumidor, para formar seu preço de venda. Segundo Bruni e Famá (2004, p. 350), "falar em preço é, ao mesmo tempo, analisar custos e estimar fatores intrínsecos do mercado em que o produto ou serviço será ofertado". Dessa forma, faz-se necessário analisar tanto o ambiente interno quanto o ambiente externo da empresa para se formar um preço de forma mais adequada.

No que se refere aos aspectos tributários, a empresa vem trabalhando com o planejamento tributário, buscando condições mais vantajosas nas suas transações. Vale ressaltar que o valor dos tributos, normalmente, é muito inflexível, uma vez que o percentual dos mesmos é estipulado pela legislação vigente. Dessa forma, a alíquota do ICMS dependerá para qual estado da federação a nota fiscal de venda será faturada; já o PIS/COFINS tem uma alíquota fixa de 9,25\% para todo país. Bruni e Famá (2004) fazem um alerta sobre os tributos serem os principais itens que devem ser analisados com cuidado na formação do preço de venda.

Com isso, verifica-se que os tributos exercem influência significativa na formação do preço de venda, uma vez que as alíquotas variam de estado para estado. Para enfrentar 0 acirramento da competitividade, é necessário criar alternativas, como a realização de um planejamento tributário de modo que o preço do produto seja acessível para o consumidor final. Uma das alternativas encontradas pela empresa em estudo foi criar centros de distribuição; como a empresa vende para todo país, em algumas situações os tributos exercem um peso muito grande na formação do preço de venda, fazendo com que o produto não chegue ao consumidor final com um preço acessível. Então a empresa criou alguns centros de distribuição em alguns estados de forma a transferir a mercadoria para esses locais e faturar a nota fiscal diretamente nesses centros. Dessa forma, o produto chega ao cliente com um preço acessível.

O custo do frete sobre vendas é calculado por quilo de produto vendido, por meio de uma estimativa, fazendo-se uma média de quantos quilos de produtos um caminhão é capaz de transportar, para, depois, fazer o cálculo de quanto determinado produto representa nesse total. Na Indústria Química Indy, o valor do frete está relacionado às vendas por região, sendo calculado por raios de distância. Assim, quanto maior o raio de distância, maior será o valor do frete. A respeito desse 
método de cálculo do frete, o diretor de vendas afirma que "não existe um modelo perfeito [...] a gente está trabalhando com um modelo que chegou-se a conclusão que era o modelo mais adequado para o estágio atual da Indy" (informação verbal).

O frete sobre vendas é outra variável que influencia significativamente a formação do preço de venda. Esse processo de apuração do valor do frete por quilo precisa ser feito com o maior cuidado possível, de forma a evitar erros que afetem diretamente o preço final dos produtos. Nesse processo de apuração do frete, é necessária uma diferenciação dos produtos menos pesados dos mais pesados. Os produtos mais pesados sofrerão maior influência do frete na formação do preço de venda, podendo chegar para o consumidor com um preço não muito competitivo e acessível.

$E$, por fim, os encargos financeiros referem-se somente às vendas a prazo, variando de acordo com o prazo concedido aos clientes. Portanto, quanto maior for o prazo dado ao cliente, maior serão os encargos financeiros incidentes sobre o valor das vendas.

Verifica-se que os custos exercem influência significativa no processo de formação do preço de venda. Faz-se necessário uma gestão de custos eficiente de forma que o preço seja formado de maneira adequada. Assim, será analisada, no próximo tópico, a influência da gestão de custos na formação do preço de venda da Indústria Química Indy.

\subsection{A Influência da Gestão de Custos na Formação do Preço de Venda}

Segundo Martins (2008), existem três elementos básicos que formam o custo de um produto: materiais diretos, mão de obra direta e custos indiretos de fabricação. Verificou-se, nos tópicos anteriores, por meio dos dados fornecidos pela empresa em estudo, que a mesma utiliza o controle na composição dos custos da matéria prima, sendo: principais matérias primas utilizadas na fabricação do produto; quantidade de cada matéria prima utilizada no processo de produção; os valores referentes ao preço pago pela matéria prima; e a unidades de medidas referentes a cada matéria prima utilizada. 
Quanto aos custos de mão de obra direta, a empresa não tem esse controle direto para a produção. A empresa tem os controles de salários, encargos e horas trabalhadas por empregados no mês. Não são alocados os custos de mão de obra diretamente aos produtos, haja vista que a empresa não possui esse controle, ou seja, a mão de obra direta da fábrica é alocada como custo fixo (indireto), utilizandose critérios de rateio. Martins (2008) afirma que o rateio contém um grau de subjetivismo, portanto, a arbitrariedade sempre vai existir nesse tipo de alocação, muitas vezes, com um nível aceitável, e, em outras, somente será aceito por não haver alternativa melhor.

Para a mensuração da mão de obra direta, a empresa deve fazer controles diretos de horas disponíveis e do tempo gasto na produção. A Indústria Química Indy possui duas linhas de produção institucional e de consumo, e a mão de obra, tanto direta como indireta, atende às duas linhas. A empresa utiliza o rateio feito considerando os departamentos de qualidade, rotulagem, manutenção, administração da fábrica, almoxarifado e esteira. Segundo informações do controller, esse rateio é feito pelo gerente de produção, o qual aponta mensalmente o percentual (rateio) dos custos de mão de obra que deverá ser alocado para cada linha de produção.

Percebe-se que não são analisadas as etapas de produção despendidas para cada produto. Considerando que a empresa produz mais de mil tipos diferentes de produtos, poderão existir diferentes etapas na produção e, consequentemente, um consumo diferenciado de mão de obra por produto.

Durante a entrevista realizada com o controller, o mesmo informou que, com base em dados históricos da empresa, estabelece-se para a formação do preço o percentual de $18 \%$ de custos fixos. Nesse percentual, estão inclusos os custos de mão de obra direta e indireta, outros custos indiretos e despesas fixas (despesas de marketing, do departamento comercial, de crédito e cobrança, financeiras, com créditos de liquidação duvidosa, entre outras). Percebe-se que a empresa apresenta dificuldades em distinguir e separar os custos fixos e custos variáveis pertinentes à produção. 
Para a análise gerencial, o método de custeio direto/variável propõe-se à avaliação da margem de contribuição por produto. Segundo Bruni (2008), a margem de contribuição é uma das principais ferramentas da gestão de custos, visto que ela analisa a relação entre receitas e gastos variáveis, eliminando o problema do rateio dos gastos indiretos. Martins (2008, p. 185) também ressalta a importância de se calcular a margem de contribuição, pois "ela tem a faculdade de tornar bem mais facilmente visível a potencialidade de cada produto, mostrando como cada um contribui para, primeiramente, amortizar os gastos fixos, e, depois, formar o lucro propriamente dito".

O controller da Indústria Indy informou que calcula a margem de contribuição dos produtos não incluindo a mão de obra direta, uma vez que a mesma é considerada como custo fixo. O mesmo também informou que analisa a margem de contribuição total, por produto e também por cliente. Nesse caso, a empresa considera no cálculo da margem de contribuição somente os demais custos e despesas variáveis, como frete, devolução de vendas, comissão e bonificação sobre vendas, os impostos, material direto, entre outros. Segundo Martins (2008) nos casos em que a mão de obra direta é contratada por um salário fixo mensal, independente se o funcionário trabalhou ou não, ela pode ser considerada como custo fixo. Porém, o que se verificou na empresa foi uma arbitrariedade no rateio desse custo; a Indy possui duas linhas de produção (consumo e institucional) e mensalmente o gerente de produção passa para o setor de controladoria 0 percentual de mão de obra direta gasto em cada linha.

Percebe-se que a gestão de custos é considerada como um dos pontos centrais para atribuir preço aos bens e/ou serviços oferecidos ao mercado e, além de fatores externos, deve orientar-se por fatores internos à organização, que são: a maximização dos lucros, o retorno do investimento e os preços baseados nos custos. Nesse sentido, a indústria em análise usufrui parcialmente dos benefícios da gestão de custos, conforme acima exposto. 
A importância da Gestão de Custos na formação do Preço de Venda: um estudo de caso em

uma indústria química de médio-grande porte

Cleuber Rafael dos Santos, Edvalda Araújo Leal, Gilberto José Miranda

\section{CONSIDERAÇÕES FINAIS}

O objetivo do trabalho foi identificar a influência da gestão de custos para a formação do preço de venda em uma indústria química de médio-grande porte situada na cidade de Uberlândia.

Verificou-se no caso estudado que a empresa possui um controle muito rígido dos custos do material direto. De acordo com o controller, é feita uma análise periódica dos custos das fórmulas dos produtos, e, caso haja alguma variação, a analista de custos procura saber o que causou isso.

A empresa calcula os fretes sobre vendas por quilo, fazendo-se uma média de quantos quilos um caminhão é capaz de transportar para, posteriormente, calcular o quanto determinado produto representa no total. De acordo com o diretor de vendas, esse seria o modelo mais adequado para o atual estágio da empresa. No entanto, percebe-se que esse modelo possui falhas, uma vez que os produtos de maior peso terão maior custo de frete sobre vendas, mesmo que tenham maior volume e, consequentemente, isso afetará a formação do preço de venda de tais produtos.

A empresa, com base em seu histórico, trabalha com um percentual de $18 \%$ para os custos fixos. Nesse percentual, estão inclusos os custos com mão de obra direta e indireta, despesas financeiras, administrativas, de marketing, de crédito e cobrança, entre outros gastos. Percebeu-se que não há uma separação entre gastos variáveis e gastos fixos e que também há um grau de arbitrariedade no rateio desses custos. Então, como uma forma de tentar solucionar esse problema, sugere-se para a empresa em estudo utilizar o Custeio $A B C$, levantando as principais etapas dentro do processo produtivo e alocando os seus gastos por meio dos direcionadores de custos.

Conforme mencionado pelo controller, a empresa utiliza a margem de contribuição para analisar a rentabilidade do negócio, sendo analisada a margem de contribuição total, por produto e por cliente. Então sugere-se para os gestores apurar as horas disponíveis e o tempo de produção, de forma a alocar o custo da mão de 
obra diretamente aos produtos. Dessa forma, há como incluir a mão de obra direta no cálculo da margem de contribuição.

As contribuições deste trabalho consistem em apresentar para os gestores da Indústria Química Indy os principais resultados deste estudo, de modo a auxiliá-los na correção de possíveis falhas no processo de formação do preço de venda. Este estudo também contribui para complementar a literatura já existente referente à gestão de custos e formação do preço de venda em indústrias de médio-grande porte, com o objetivo de mostrar para os gestores a influência da gestão de custos na formação do preço de venda. Para pesquisas futuras, sugere-se aplicar este estudo em um número maior de indústrias, visando à comparação dos resultados obtidos.

\section{REFERÊNCIAS}

ABIQUIM. (2011). Dados da indústria química brasileira. Disponível em: $<$ www.abiquim.org.br>. Acesso em: 03/nov.

ANDRADE, M. M. (2004). Como preparar trabalhos para cursos de pós-graduação: noções práticas. (6 ed.). São Paulo: Atlas.

BANCO NACIONAL DE DESENVOLVIMENTO. Porte de empresa. Disponível em: < http://www.bndes.gov.br/SiteBNDES/bndes/bndes_pt/Navegacao_Suplementar/Perfil /porte.html>. Acesso em: 30/abril/2012.

BRAGA, D. P. G et al. (2010). Gestão de custos, preços e resultados: um estudo em indústrias conserveiras do Rio Grande do Sul. Revista Contabilidade, Gestão e Governança - UNB, Brasília, v.13, n.2, p. 20-35, Maio/Ago.

BRUNI, A. L. (2008). A Administração de custos, preços e lucros. (2 ed.). São Paulo: Atlas.

BRUNI, A. L.; FAMÁ, R. (2004). Gestão de custos e formação de preço: com aplicações na calculadora HP 12C e Excel. (3 ed.). São Paulo: Atlas.

CARDOSO, R. S.; BEUREN, I. M. (2010). Gestão de custos de matérias-primas em indústrias de conserva de pescado do Brasil e da Espanha. Revista ABCustos, v.5, n.2, p. 29-44, Maio/Ago.

COLAUTO, R. D.; BEUREN, I. M. In: BEUREN, I. M. (Org.). (2008). Como elaborar trabalhos monográficos em contabilidade: teoria e prática. (3 ed.). São Paulo: Atlas. 
GIL, A. C. (2002). Como elaborar projetos de pesquisa. (4 ed.). São Paulo: Atlas.

HORNGREN, C.T. et al. (2004). Contabilidade de Custos: uma abordagem gerencial. V. 1. 11. ed. São Paulo: Prentice Hall.

IUDICIBUS, S.; MARION, J. C. (2008). Introdução a teoria da contabilidade. (4 ed.). São Paulo: Atlas.

LEONE, G. S. G. (2000). Custos: planejamento, implantação e controle. (3 ed.). São Paulo: Atlas.

MACHADO, D. G.; SOUZA, M. A. (2006). Análise das relações entre a gestão de custos e a gestão do preço de venda: um estudo das práticas adotadas por empresas industriais conserveiras estabelecidas no RS. Revista Universo Contábil, Blumenau, v. 2, n. 1, p. 42-60, jan-abr.

MARTINS, E. (2008). Contabilidade de Custos. (9 ed.). São Paulo: Atlas.

MARTINS, G. A. (2008). Estudo de caso: uma estratégia de pesquisa. (2 ed.). São Paulo: Atlas.

PADOVEZE, C. L. (2004). Contabilidade Gerencial: Um enfoque em sistema de informação contábil. (4 ed.). São Paulo: Atlas.

PUFF, J.et al. (2006). Custos e formação do preço de venda em uma indústria de portas e janelas termo-acústicas. In: SEMINÁRIO DE CIÊNCIAS CONTÁBEIS, 2. 22 a 24 ago. Blumenau. Anais eletrônicos...Blumenau: FURB, 2006. Disponível em:< http://www.sabercontabil.pro.br>. Acesso em: 09/set/2011.

RAUPP, F. M.; BEUREN, I. M. In: BEUREN, I. M. (Org.). (2008). Como elaborar trabalhos monográficos em contabilidade: teoria e prática. (3 ed.). São Paulo: Atlas.

RIBEIRO, O. M. (2009). Contabilidade de Custos. São Paulo: Saraiva.

RICHARDSON, R. J. (1989). Pesquisa social: métodos e técnicas. (2 ed.). São Paulo: Atlas.

YIN, R.K. (2005). Estudo de Caso: planejamento e método. Porto Alegre: Bookman.

Data de Submissão: 14/12/2012

Data de Aceite: 27/02/2014 